This item was submitted to Loughborough's Research Repository by the author.

Items in Figshare are protected by copyright, with all rights reserved, unless otherwise indicated.

\title{
A miniature reconfigurable printed monopole antenna for WLAN/WiMAX and LTE communication bands
}

PLEASE CITE THE PUBLISHED VERSION

http://dx.doi.org/10.1109/LAPC.2012.6403089

PUBLISHER

(C) IEEE

VERSION

AM (Accepted Manuscript)

\section{PUBLISHER STATEMENT}

This work is made available according to the conditions of the Creative Commons Attribution-NonCommercialNoDerivatives 4.0 International (CC BY-NC-ND 4.0) licence. Full details of this licence are available at: https://creativecommons.org/licenses/by-nc-nd/4.0/

\section{LICENCE}

CC BY-NC-ND 4.0

\section{REPOSITORY RECORD}

Yadav, Ajit M., C.J. Panagamuwa, and R.D. Seager. 2019. "A Miniature Reconfigurable Printed Monopole Antenna for Wlan/wimax and LTE Communication Bands”. figshare. https://hdl.handle.net/2134/26565. 


\title{
A Miniature Reconfigurable Printed Monopole Antenna for WLAN/WiMAX and LTE Communication Bands
}

\author{
A.M.Yadav, C.J.Panagamuwa, R.D.Seager \\ Wireless Communications Research Group \\ School of Electronics, Electrical and Systems Engineering \\ Loughborough University, Loughborough United Kingdom \\ $\underline{\text { A.Yadav2@1boro.ac.uk,C.J.Panagamuwa@lboro.ac.uk, R.D.Seager@1boro.ac.uk }}$
}

\begin{abstract}
A reconfigurable printed monopole antenna covering WLAN, LTE, WiMAX and HiperLAN communication bands is presented in this paper. The antenna operates between these frequencies with activation of 2 switches. The proposed antenna is a low profile, miniaturised design and occupies a volume of 20 $\times 25 \times 0.5\left(25 \mathrm{~mm}^{3}\right)$ which makes it an ideal candidate to slot into compact and portable devices. Initial results including antenna design, S-Parameters, Radiation Characteristics and Peak gain at different frequencies is presented and discussed.
\end{abstract}

Keywords- switchable printed antenna, frequency reconfigurability, switches, minature antenna, top loaded monopole antenna, planar antenna

\section{INTRODUCTION}

In the last few years, there has been a large proliferation in the popularity of small and compact wireless communication devices like smart phones and tablets. This coupled with the arrival of new communications standards such as LTE and WiMAX, has put tremendous pressure on antenna engineers to develop miniature printed antennas supporting different wireless communication standards. Multiband and wideband antennas have been presented and discussed widely in various studies [1-5]. However these antennas require stringent filtering in order to differentiate between various bands of interest. Other issues like volume constraints, combined with important metrics like radiation efficiency makes antenna design challenging and daunting.

Frequency reconfigurable antennas could provide a solution to the challenges associated with multiband and wideband antennas [6]. Frequency reconfigurable antennas can be switched or tuned to operate in different communication bands The major advantage of this technique is that it provides pre-filtering, thus relaxing some of the constraints on the system's filter design.[7]. However the challenges associated with frequency reconfigurable antennas is that they may need a number of active components on the antenna to achieve the reconfiguration which may lead to an increase in the complexity and power consumption. Achieving switching or tuning across the bands with a minimum number of active components is desirable. Some of the main requirements of frequency reconfigurable antennas for such devices are miniaturization, low profile and excellent radiation characteristics.
With this motivation, we present a conventional $\lambda / 4$ printed monopole reconfigurable antenna which is modified into meander lines in order to save volume on the substrate and making it more compact. The proposed antenna operates in 4 distinct wireless communication bands, namely WLAN, LTE, WiMAX and HiperLAN with use of only 2 switches. The antenna in question is a low profile, miniature design that could be easily integrated to portable devices such as laptops and tablet computers.

\section{ANTENNA DESIGN}

The top view of the proposed antenna is shown in Figure 1

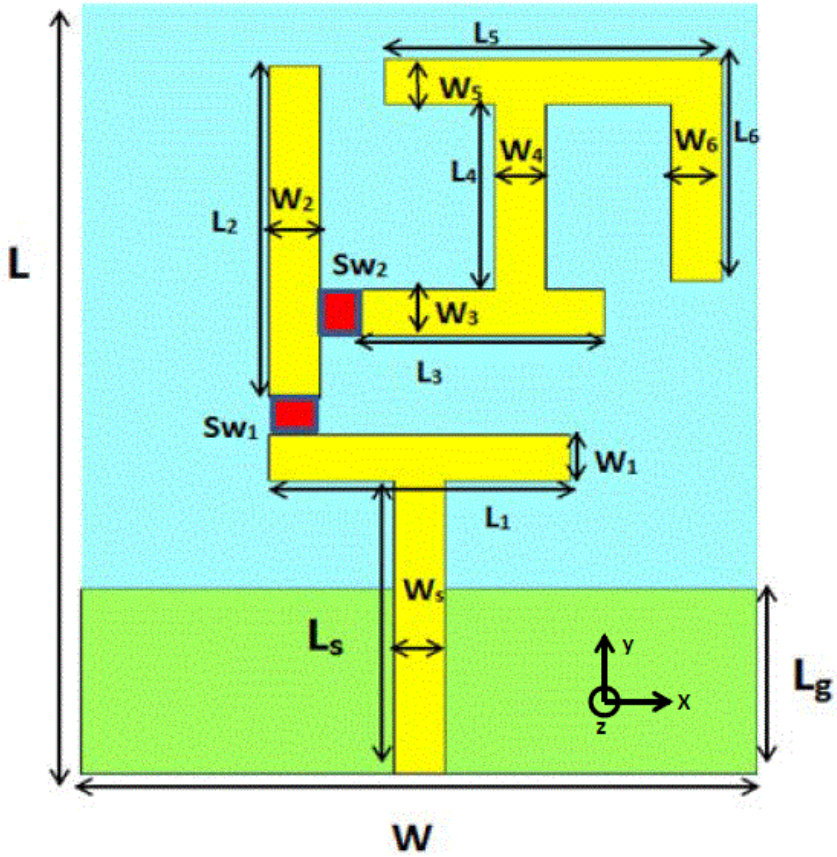

Figure 1. Geometry of the proposed antenna

It is a top-loaded monopole antenna printed on a substrate of dielectric constant 3.5 and thickness $0.5 \mathrm{~mm}$. The antenna is fed with $50 \Omega$ microstrip transmission line backed with a ground plane (showed in green) of $20 \times 6 \mathrm{~mm}$. Full dimensions of the antenna are given in TABLE I. Two gaps are created on the antenna structure as shown in Figure. 1 to 
accommodate switches. Copper strips are used as switches as a proof-of-concept in order to bridge the gaps. This changes the electrical length of the antenna, creating different current paths and resonant frequencies.

TABLE I. ANTENNA DIMENSIONS

\begin{tabular}{|c|c|}
\hline Parameters & Dimensions $(\mathrm{mm})$ \\
\hline $\mathrm{L}_{\mathrm{S}}$ & 10 \\
\hline $\mathrm{W}_{\mathrm{S}}$ & 1.5 \\
\hline $\mathrm{L}_{1}$ & 8.9 \\
\hline $\mathrm{W}_{1}$ & 1.5 \\
\hline $\mathrm{L}_{2}$ & 10.95 \\
\hline $\mathrm{W}_{2}$ & 1.5 \\
\hline $\mathrm{L}_{3}$ & 8.9 \\
\hline $\mathrm{W}_{3}$ & 1.5 \\
\hline $\mathrm{L}_{4}$ & 8.9 \\
\hline $\mathrm{W}_{4}$ & 1.5 \\
\hline $\mathrm{L}_{5}$ & 10 \\
\hline $\mathrm{W}_{5}$ & 1.5 \\
\hline $\mathrm{L}_{6}$ & 6 \\
\hline $\mathrm{W}_{6}$ & 1.5 \\
\hline & \\
\hline
\end{tabular}

\section{PRINCIPLE OF OPERATION}

The antenna is simulated numerically and optimised using a full-wave electromagnetic simulator, CST Microwave Studio2010 [8]. The proposed antenna operates in 3 modes with use of 2 switches. The operating frequencies corresponding to the 3 modes are given in TABLE II.

TABLE II. SWITCH CONFIGURATION

\begin{tabular}{|c|c|c|}
\hline \multicolumn{2}{|c|}{ Switch Configuration } & Operating frequency $(\mathrm{GHz})$ \\
\cline { 1 - 2 }$S w_{1}$ & $S w_{2}$ & \\
\hline 0 & 1 & $5.0-6.0$ \\
\hline 1 & 0 & $3.3-3.6$ \\
\hline 1 & 1 & $2.4-2.6$ \\
\hline
\end{tabular}

The switch affects the current path resulting in change of the electrical length of the ant enna. The equivalent antenna with surface current distributions in all 3 modes of operation is shown in the Figure $2-4$.

When only $\mathrm{Sw}_{2}$ is $\mathrm{ON}$, the antenna equates to a T-shaped monopole of approximately $\lambda / 4$ wavelength $\left(\mathrm{L}_{\mathrm{S}}+\mathrm{L}_{1}\right)$. Of all three modes, this structure has the shortest electrical path length and so it resonates at the higher frequency band around $5.2 \mathrm{GHz}$, covering HiperLAN as can be seen in 0 , the current is maximum on the T-section with minor coupling to the parasitic top element.

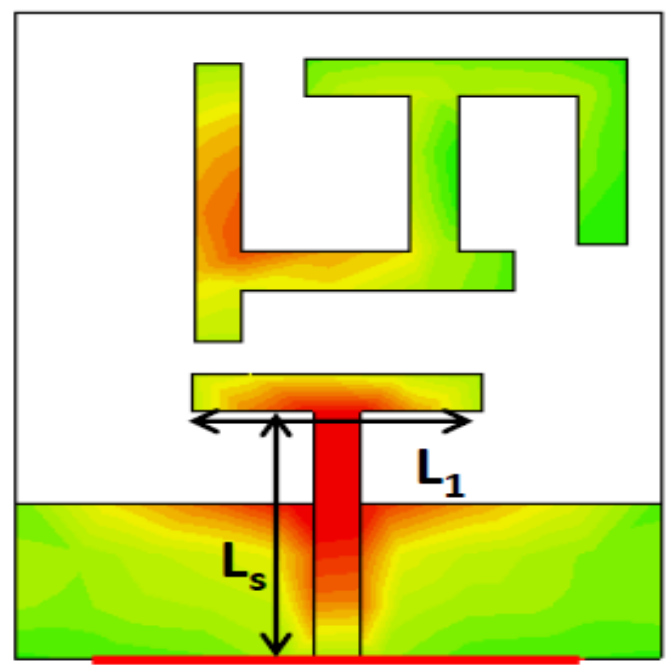

Figure 2. Surface current distribution for mode 1 when Sw2 is ON

In mode 2, where only $\mathrm{Sw}_{1}$ is $\mathrm{ON}$, the electrical length (overall length is approximately $\lambda / 4$ at $3.4 \mathrm{GHz}$ ) is increased and the antenna takes the shape of a L-shaped monopole .With a slightly longer current path $\left(\mathrm{L}_{\mathrm{S}}+\mathrm{L}_{1}+\mathrm{L}_{2}\right)$, the antenna resonates in the mid-band frequency, covering the 3.3 to 3.6GHz WiMAX band as can be seen in figure 3 . It can be observed very little current is excited on the parasitic branch to the right.

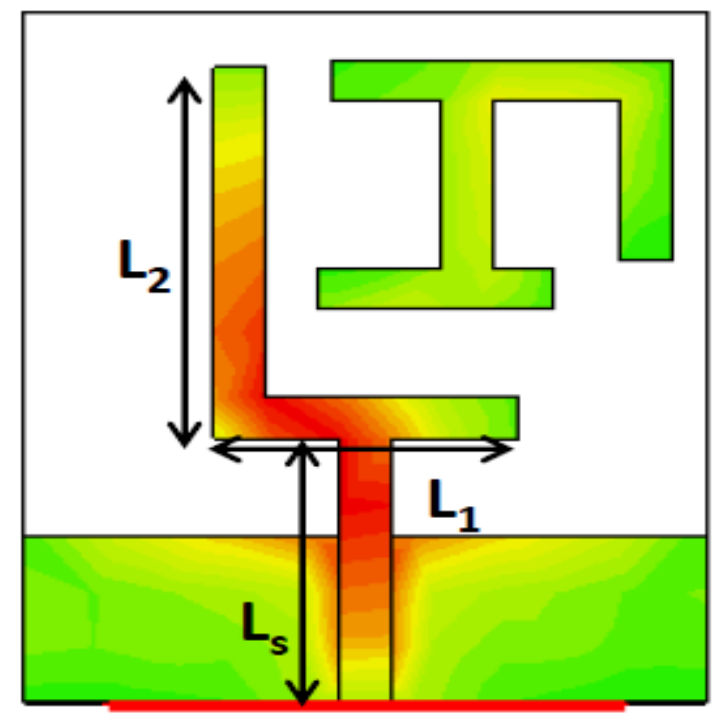

Figure 3. Surface current distribution for mode 2 when $\mathrm{Sw}_{1}$ is $\mathrm{ON}$ 


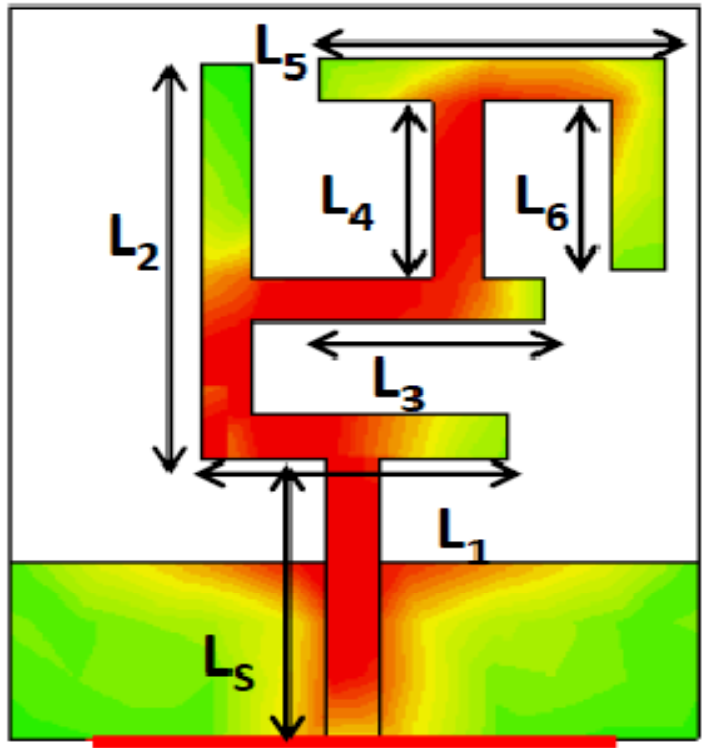

Figure 4. Surface current distribution for mode 3 when both switches are ON

The antenna is the longest $\left(\mathrm{L}_{\mathrm{S}}+\mathrm{L}_{1}+\mathrm{L}_{2}+\mathrm{L}_{3}+\mathrm{L}_{4}+\mathrm{L}_{5}+\mathrm{L}_{6}\right)$ in mode 3 where both switches are ON. The antenna operates at a narrow band of 2.4-2.6GHz which can be used for WLAN and LTE applications.

IV. SIMULATION RESULTS

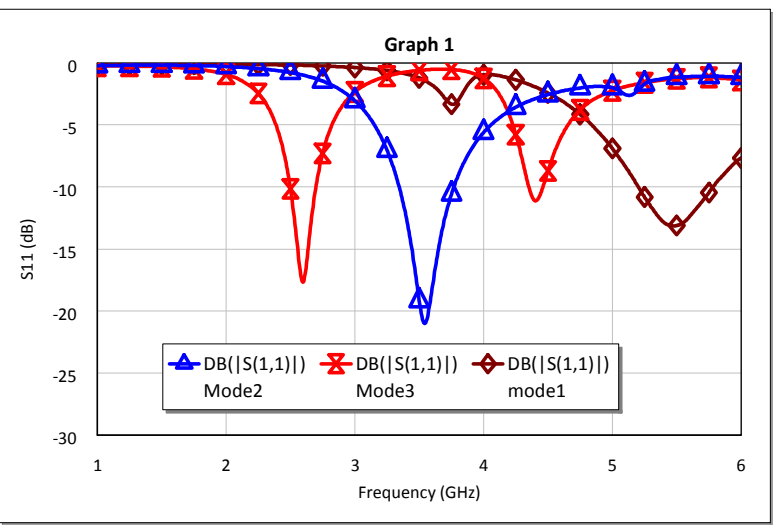

Figure 5. Simulated results for $\mathrm{S}_{11}$ for the Proposed antenna

The simulated $S_{11}$ results given in Figure 5 show the resonant frequencies of the 3 modes. As indicated on the graph, the match is better than $-10 \mathrm{~dB}$ for all the covered frequency bands. Simulated results of peak gain and radiation efficiency are presented in TABLE III. The 3-D radiation patterns are also shown in Figure 6-8. Corresponding to the 3 modes of operation at $5.2 \mathrm{GHz}, 3.4 \mathrm{GHz}$ and $2.4 \mathrm{GHz}$ respectively.
TABLE III. PEAK GAIN AND RADATION EFFICENCY IN ALL MODES OF OPERATION

\begin{tabular}{|c|c|c|}
\hline $\begin{array}{c}\text { Switch } \\
\text { Configuration }\end{array}$ & $\begin{array}{c}\text { Peak Gain } \\
(d \mathrm{~B})\end{array}$ & $\begin{array}{c}\text { Radiation } \\
\text { efficiency }(\%)\end{array}$ \\
\hline Mode 1 & 1.75 & $84 \%$ \\
\hline Mode2 & 1.61 & $85 \%$ \\
\hline Mode3 & 1.32 & $83 \%$ \\
\hline
\end{tabular}

The radiation pattern for all the 3 modes is a doughnut shape expected from a printed monopole antenna.

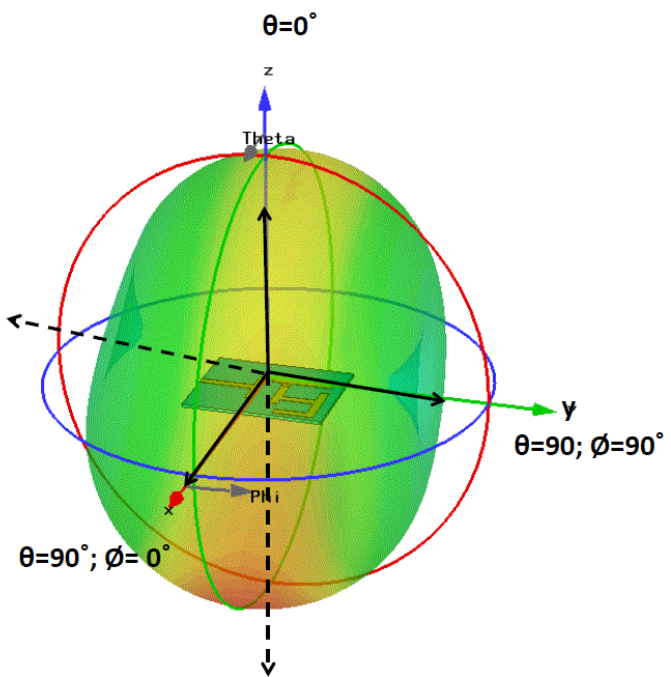

Figure 6 3D Radiation Pattern at 5.2 $\mathrm{GHz}$ corresponding to mode 1 of the switching configuration.

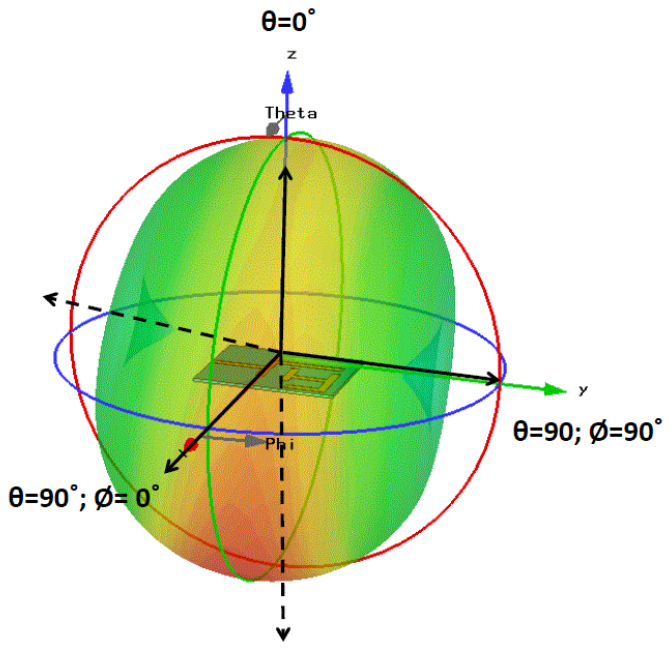

Figure 7. 3D Radiation Pattern at $3.4 \mathrm{GHz}$ corresponding to mode 2 of switching configuration 


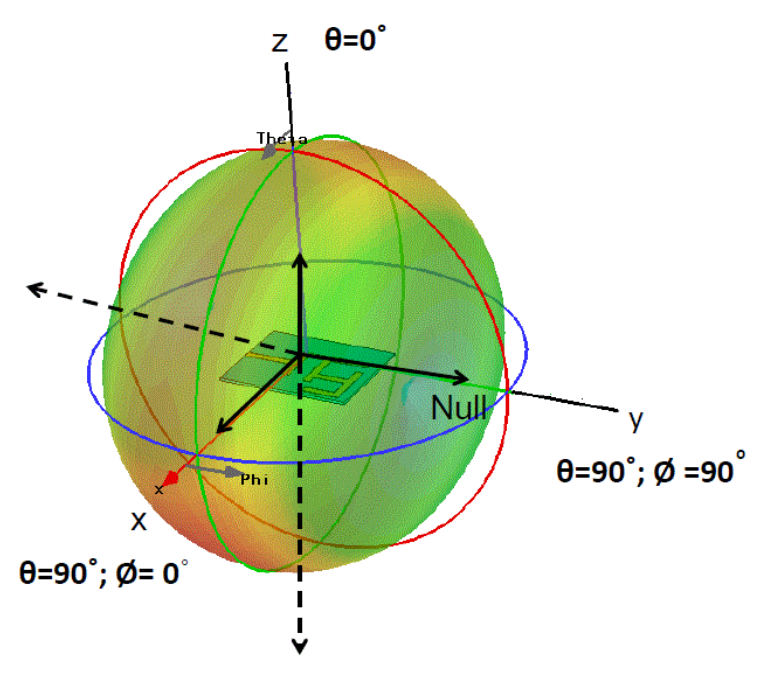

Figure $83 \mathrm{D}$ Radiation pattern at $2.48 \mathrm{GHz}$ corresponding to mode 3 of switching configuration

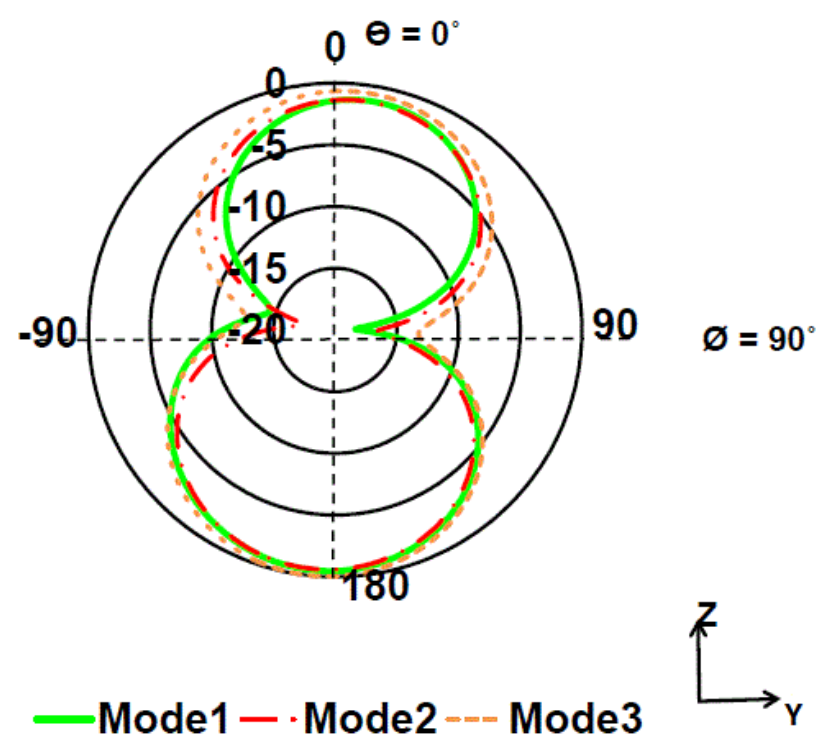

Fig: 9 2D Radiation Pattern for all modes of operation

Maximum radiation is in the -zx plane and nulls can be observed on y-axis. The radiation patterns at all 3 modes are similar.
The proposed antenna is a variation of a conventional $\lambda / 4$ printed monopole antenna which is folded into meander lines. Engaging the switches, the length of the antenna can be changed resulting in 4 different operating bands covering WLAN, LTE, WiMAX and HiperLAN. The reconfigurable nature of the antenna provides pre-filtering, thus relaxing some of the constraints on the system's filter design. The gain and radiation efficiency of the antenna is almost same in all modes of operation. Since the antenna is of a compact volume it can be easily slotted into the screens of laptops and tablet computers.

\section{FUTURE WORK}

Future work is targeted to fabricate the prototype and incorporate practical switches on the antenna. The use of optically controlled microwave switches [9] and PIN diodes can be investigated. Another aspect of future work will be concentrated on performing electromagnetic visibility studies (EVS) in order to optimize the location and position of antenna on laptop and tablet screens.

\section{REFERENCES}

[1] T.Ito, H.Moriyasu and M.Matsui, " A small antenna for laptop applications" proceedings IEEE Workshop on Antenna Technology, Small Antennas and Novel Metamaterials, pp.233-236, March 2006

[2] J.M.Johnson and Y.Rahamat Samii, " Wideband tab monopole antenna array for wireless adaptive and mobile information systems applications, Proc.IEEE Int.symposium Antennas Propagation vol.1, pp 718-721, July 1996

[3] J.Antoniuk, A.A.Moreira and C.Peixeiro, L-Bent omni-directional patch antenna for wireless applications in laptop computers, Proc.IEEE int.symposium.Antennas Propagation vol.4A, pp 355-359, July 2005.

[4] Yu-Jen Chi; Chien-Wen Chiu; Sheng-Ming Deng; , "An internal multiband inverted-F antenna for laptop applications," Antenna Technology, 2009. iWAT 2009. IEEE International Workshop on , vol., no., pp.1-4, 2-4 March 2009

[5] Cheng-Tse Lee; Kin-Lu Wong;, "Small-size printed coupled-fed PIFA with an embedded band-notching slit for internal WLAN/WiMAX laptop computer antenna," Antennas and Propagation Society International Symposium, 2009. APSURSI '09. IEEE, vol., no., pp.1-4, 1-5 June

[6] Pan, H.K.; Tsai, J.; Martinez, J.; Golden, S.; Nair, V.K.; Bernhard, J.T.; , "Reconfigurable antenna implementation in multi-radio platform," Antennas and Propagation Society International Symposium, 2008. AP-S 2008. IEEE , vol., no., pp.1-4, 5-11 July 2008

[7] Hall, P.S.; Gardner, P.; Kelly, J.; Ebrahimi, E.; Hamid, M.R.; Ghanem, F.; Herraiz-Martinez, F.J.; Segovia-Vargas, D.; , "Reconfigurable antenna challenges for future radio systems," Antennas and Propagation, 3rd European Conference on , vol., no., pp.949-955, 2009

[8] CST Studio Suite 2010, Reference Manual, Computer Simulations Technology, http:// www.cst.com

[9] C.J. Panagamuwa; A.Chauraya; J.C.Vardaxoglou; , "Frequency and beam reconfigurable antenna using photoconducting switches," Antennas and Propagation, IEEE Transactions on, vol.54, no.2, pp. 449- 454, Feb. 2006 